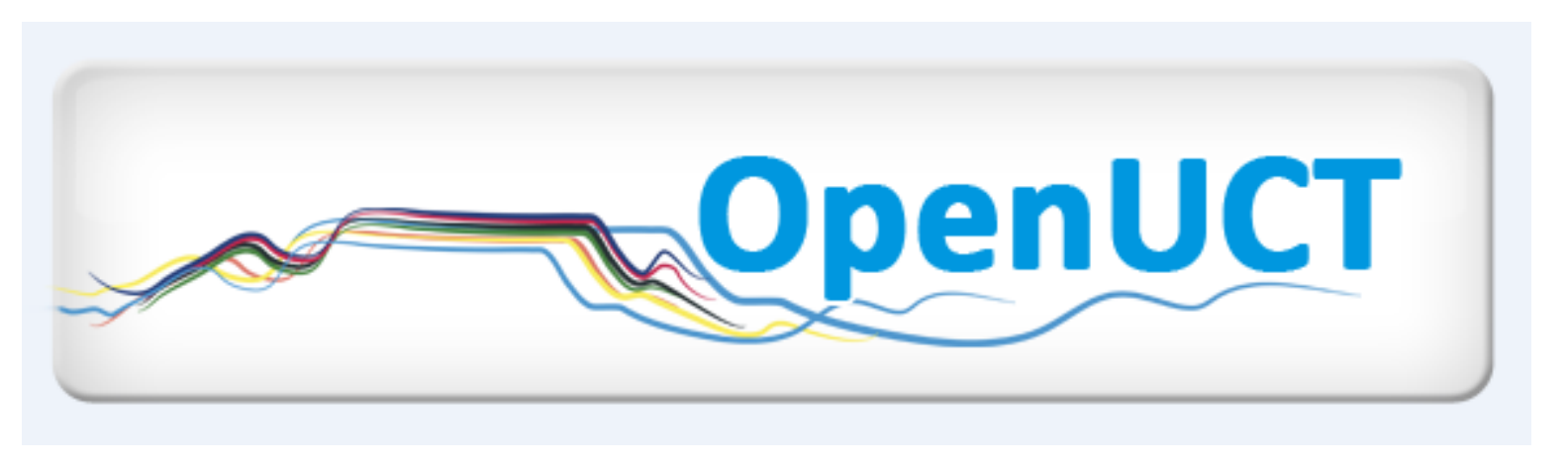

This is the author-approved manuscript version of a journal article published in:

Archer. A. 2007. 'No goats in the mother city': using Symbolic Objects to help students talk about diversity and change. English in Education. 41(1): 7-20. DOI:

10.1111/j.1754-8845.2007.tb00806.x.

It is made available under the terms of agreement between the author and the journal, and in accordance with the University of Cape Town's Open Access Policy for the purposes of research, teaching and private study.

http://www.openuct.uct.ac.za/sites/default/files/UCTOpenAccessPolicy.pdf 


\title{
'No goats in the mother city': using Symbolic Objects to help students talk about diversity and change
}

\author{
Dr Arlene Archer \\ Writing Centre, University of Cape Town, South Africa \\ Arlene.Archer@uct.ac.za
}

\begin{abstract}
This paper reports on a first year project in a South African engineering foundation programme which attempted to bring a cultural studies perspective to teaching academic literacy. Students identify and investigate everyday objects that have symbolic meanings in their communities. Objects are seen as catalysts for enabling student narratives to emerge, and are a way of exploring the tensions between convention and change in cultural practices. A project such as these breaks disciplinary frames, working across diverse contexts such as engineering and cultural studies. The aim is to begin to explore some of the complexities around 'development' in contexts of diversity and change, globalization and relocalization.
\end{abstract}

\section{Key Words}

Cultural studies, academic literacies, symbolic objects, less regulated spaces 
In this paper I theorize the using of objects as a way of exploring notions of culture, cultural practices and change in the classroom. For this, I have looked towards cultural studies which centres on the practices and texts of culture, and looks at their relationships to social groups. Although eclectic in its approach, broadly-speaking cultural studies seeks to understand 'the relationships of cultural production, consumption, belief and meaning, to social processes and institutions' (Lister and Wells 2001: 61). I report on a 'cultural studies' project in a first year Communication Course in a South African engineering foundation programme which caters for students from less advantaged educational backgrounds. The programme structures the students' learning experience by extending the period of study and by including courses aimed at developing academic literacy practices. The course focuses on sustainable development in rural areas, concentrating on housing, transport, power, water provision and protection. Through the processes of researching and writing about rural development, academic literacy practices are explicitly taught to the students, such as argument, referencing conventions, scientific discourse.

In order to introduce certain topics around development, such as cultural relativity, power dynamics, appropriacy for context, relationships to landscapes, the course begins with a project that focuses on symbolic objects. In the project, students identify everyday objects that have symbolic meanings within their communities and examine these in a range of physical, cultural and communication 'landscapes'. In this context, objects are seen as catalysts for enabling student narratives and understandings to emerge. A project such as this works across diverse disciplinary contexts such as engineering and cultural studies, in order to begin to explore some of the complexities around 'development' in a country like South Africa which is engaged in processes of rapid transition.

Recontextualization of meaning through symbolic objects I wanted the students to talk about themselves and their backgrounds, particularly their relationships to 'home' before discussing 'development' issues. About a third of the 80 students in the class are from rural areas - often particularly poor areas in the South African context. However, getting students to speak about their life histories, past experiences and values is not a simple and straightforward process. It often felt fraught, highlighting the diversity in the classroom along the lines of class, race and the rural/urban divide, and resulted in either bland depictions or over-the-top stereotypes. Also, as Bangeni and Kapp (2005) have argued, students develop increasingly ambivalent relationships to home as they become more enmeshed in the cultures and environments of the university. It is clear that any narrative does not so much reflect 'the truth' as construct it in a particular way. However, Hoskins argues that 'even if we accept the highly invented and 
constructed nature of any such narrative, we must address the relationship between experience and representation' (1998: 6). I began to think of different ways of encouraging students to talk about themselves and their communities, using objects as metaphors to elicit an indirect account of personal experience. It seemed to me that discussions around objects seemed to open up dynamic processes within students, and between the students and the total environment more than narrative accounts or 'life histories' did. From this perspective, objects are seen as 'reflections of the wider lives of communities and individuals' (Emmison and Smith 2000: 111).

In thinking about the affordances of objects in opening up classroom discussions, I usefully encountered Hoskins' (1998) work with the Kodi of the Eastern Indonesian island of Sumba. She also noted that the Kodi people did not tell their lives directly, but found that objects were metaphors to elicit an indirect account of personal experience. She argues that the stories generated around objects 'provide a distanced form of introspection, a way of discussing loaded sexual politics in an ironic mode, and a form of reflection on the earning of one's own life' (Hoskins 1998: 2). My hope was that the discussions around various objects would open up the role of objects in people's definition of who they are and who they have been. 'The same culturally legitimised object might provide only fleeting comfort to one person, whereas to another it signified complex emotional and cognitive ties to other people and ideas' (Csikszentmihalyi, and Rochberg-Halton 1981: x). What I attempted to do in the Symbolic Object project then, along the lines of Hoskins, was to focus on the 'narrative creation of the self through the vehicle of an object' (1998: 24).

Perhaps differently to Hoskins, I saw the link to 'place' as important and became particularly interested in the recontextualization of objects from 'home' or other contexts to the environments of first year students at a tertiary institution. New meanings are created through recontextualization (Bernstein 1996, ledema 1999, Kell 2006), familiar objects are 'made strange' by examining them in new contexts, and objects can become catalysts for talking about change in the classroom. For instance, one student commented on the meaning of 'clothes' in his community, and how their meaning had shifted in the new context he found himself in:

People at home are classified according to the price of the clothes they wear. And in many cases, birds of feather flock together... Like when a person dresses like the rap artists in the States, it's probably because they belong to a group of people who are really fans of rap music. The meaning has changed altogether [at the university]. Clothes don't really mean anything here and its really weird because I was already used to the idea that clothes define a person. 
The student is clearly grappling with the array of possible meanings available in the new context of the university.

Besides the notion of biographical objects, I saw objects as a refracted way of engaging with varying cultural practices in the classroom. The construction of the concept of 'culture' in the Communication Course is not as a static, reified 'entity', linked to the nation state, or groups within that. Nor is 'culture' seen as the preserve of the elite (culture as opera, ballet and art) or the Other (cultures of rural or 'traditional' societies). Contemporary cultural studies sees 'culture' as 'contested yet creative, limiting but empowering, stable yet transformed and transforming, compromised yet valid, bounded but always transcending boundaries' (Thornton 2000: $44-45$ ). The assumption underlying the course is that 'culture' is dynamic, always contested, and any practice of culture involves some element of control, coercion or power. In fact, social power exists in the rituals, practices and customs of everyday life and the ordinary (Foucault 1972). De Certeau (1998) emphasizes that these 'unnoticed' practices ensure that people discipline themselves, and maintain notions of order and 'propriety'. Cultural Studies is concerned with the analysis of these practices in the context of 'the relations of power which condition their production, circulation, deployment and ...effects' (Bennett 1998: 60). Through discussions on symbolic objects and rural development, the course attempts to situate particular cultural practices within the broader systems of meaning and values that sustain them, and attempts to highlight cultural practices as complex sets of meaning that are in tension with each other.

Introducing the Symbolic Object project

The course begins with an attempt at thinking about different aspects of 'communication'. Three categories emerge, namely media of communication (telephones, faxes, radio, TV), genres of communication (letters, e-mails, newspaper articles) and modes of communication (talking, images, music). By 'mode' I mean the culturally shaped material available for representation, such as visual mode, written mode, oral mode (Kress 2000). Modes, media and genres form part of what Kress and Van Leeuwen (1996) call the 'semiotic landscape', namely the range of forms or modes of public communication available in a society, and their uses and valuations. In order to explore this idea of 'semiotic landscape', we look at students' names and their meanings. The name exercise is another way of exploring home, cultural practices and students' resources. It allows students to recontextualize meanings by examining the familiar in the unfamiliar context of the classroom. In this sense, the name exercise is a version of the Symbolic Object project, but perhaps easier for students to access. It thus works well as a scaffolding exercise in introducing the Symbolic Object project. 
We look at an example, Chinua Achebe, and how he chose from the resources available when changing his name from Albert Chinualumogu. He changed his name as a statement of identity as, for him, 'Albert' pointed to a connection with British colonialism, and 'Chinualumogu' evoked a traditional African past (Achebe 1975: 67). The name 'Chinua Achebe' appeared more global for him, more corporate and thus removed from the cultural and historical baggage of the past. The ensuing discussion around names in the class is extremely rich and generative. For instance, one student's name meant 'lucky' as his mother was the first in the family to give birth to a son. His second name also meant a version of this, 'a gift'. Another student spoke about his surname - how at the time of the Mfecane his family moved down to a certain area, and his great grandfather changed his name to become the chief of the area. Another student went to an Afrikaans school and therefore adopted her second name, which was not Xhosa, but an English name. It is clear that in talking about the names and nicknames given them, people create meaning from their available resources in order to make statements about themselves and their communities.

Following this discussion, I introduce the Symbolic Objects project to the class. In groups, the students need to identify everyday objects that have symbolic meanings in their communities. The groups produce a text which discusses the physical characteristics and uses of an object, as well as the symbolic, social and cultural meanings people attach to it. The students are able to choose between predominantly written modes, or predominantly visual modes (such as posters, photos, video, 3-dimensional constructions). They write a brief justification for their choice of 'mode' of production and think about the relevance of the project for themselves as future engineers. Although the parameters of the task were very broad, the projects were assessed according to the following criteria: the exploration of the concept in relation to physical, cultural and communicational landscapes; the quality of research, interviews and observations; the appropriacy of the choice of mode of presentation and the reflections thereon. This emphasis on student reflection was an attempt to counteract the technocist tendency in assessment practices and to see the Symbolic Object texts as process, rather than product (see Appendix A). 
Indexing tensions between convention and change

The students identified a range of everyday objects with symbolic meanings. See figure 1 below.

\begin{tabular}{|c|c|}
\hline $\begin{array}{l}\text { Technological 'objects' } \\
\text { - Electricity } \\
\text { - Tractors/ploughing equipment } \\
\text { - Cars } \\
\text { Natural objects } \\
\text { - Flowers } \\
\text { - Jacaranda leaf } \\
\text { - Trees } \\
\text { - Dove } \\
\text { - Lion/leopard skin } \\
\text { - Goat } \\
\text { Objects relating to Crime } \\
\text { - burglar bars } \\
\text { - barbed wire } \\
\text { - broken glass } \\
\text { - gun } \\
\text { Political Objects } \\
\text { - ANC flag } \\
\text { - Statue of king Shaka } \\
\text { Objects representing illness } \\
\text { - AIDS ribbon symbol }\end{array}$ & $\begin{array}{l}\text { Bodily adornments } \\
\text { Clothes } \\
\text { - designer labels } \\
\text { - short skirts } \\
\text { - pants (on women) } \\
\text { - black clothes (mourning) } \\
\text { - uniforms (school/police) } \\
\text { - hat } \\
\text { Jewellery } \\
\text { - rings } \\
\text { - chains } \\
\text { - beads } \\
\text { - goat's hair necklaces } \\
\text { Dot worn on forehead } \\
\text { Dreadlocks } \\
\text { Miscellaneous objects } \\
\text { - road signs } \\
\text { - soccer ball } \\
\text { - beer } \\
\text { - cigarettes } \\
\text { - photographs } \\
\text { - music }\end{array}$ \\
\hline
\end{tabular}

Figure 1: Types of objects students identified

The way that students framed and discussed many of these objects pointed to tensions between convention and change. Shifts and contradictions in certain cultural practices were highlighted, such as in the ways of wearing one's hair, of slaughtering a goat, of adorning the face. These contradictions focused mainly on gender, race, generational conflict, urban/rural traditions, the individual and the collective. For instance, dreadlocks in South African society have different meanings for different contexts. Although many students recognized dreadlocks as a 'fashion' item, they also highlighted issues of religion, generation, class, cultural groupings. In terms of religion, one student argued that 'Christians regard the person with dreadlocks as an embarrassment to the community, as being dirty and as having no regard or respect for God. Muslims are not allowed to grow dreadlocks and if you are to go ahead and make dreadlocks your friends and family 
automatically disown you. On the other hand, 'for Rastafarians having dreadlocks is who they are, it is their way of being able to be distinguished from other people'. The students mentioned that some 'traditional' doctors also have dreadlocks, thus recognizing the physical expression of the spiritual. The students highlighted that the hairstyles one chooses often result in inter-generational conflict: 'Some parents do not allow their children to do them [dreadlocks] because they think they are deviating from their culture and end up smoking marijuana'. The question of 'race' came up often, which is perhaps to be expected in a society with South Africa's history: 'Dreadlocks function differently in different communities, like most multiracial schools in South Africa do not accept dreadlocks because of the perception that they are untidy and unacceptable to the white community'. The student here also replicates some of the stereotypes circulating in society by conceptualizing white people as a defined collective with fixed opinions. However, she does recognize that people break these stereotypes: 'Nowadays white people are also doing them because they think they are cool'.

Another group of students chose the 'goat' as object and the practice of sacrificial slaughter for their strong symbolic significance in a particular social setting. According to Douglas, the structures of living organisms reflect complex social forms better than inanimate objects. In rituals of sacrifice, the kind of animal to be used is specified (male or female, black or white, old or young) (1966: 114). Slaughtering a goat enacts a range of societal and spiritual functions. It can function to communicate with the ancestors as a form of ritual purification (for example, if a woman's husband dies she can 'purify' herself with the goat's large intestine). It can also function as celebration. According to one of the students in the group,

even when I go [home] like in the holidays, sometimes they slaughter a goat ... like, you see during Christmas, ja, she [his grandmother] does that, but not every year. It is something like a celebration. We're just thanking our forefathers for what they've done for us.

The mentioning of the grandmother slaughtering the goat raises an interesting question about gender and change, as it is traditionally the men that perform the ritual sacrifice. The goat also functions as an indicator of social status and of power in a particular community. This is reflected in the following student statement: 
The goat also provides a man (especially the fathers of their family) with some admiration by the society when he has lot of them ... The goats show some kind of being rich of a particular family in rural areas, when they are filling almost all the space in the kraal. This is because the animal can be sold or used for some very expensive cultural practices like lobola .

Although slaughtering a goat is a practice dating from pre-colonial economies, it is prevalent in our society today, but is becoming more and more a contested cultural practice. For instance, when Peggy-Sue Khumalo was crowned Miss South Africa, she announced that she would sacrifice a white goat to celebrate and this caused animal activists to go up in arms (Barnard 2000: 348).

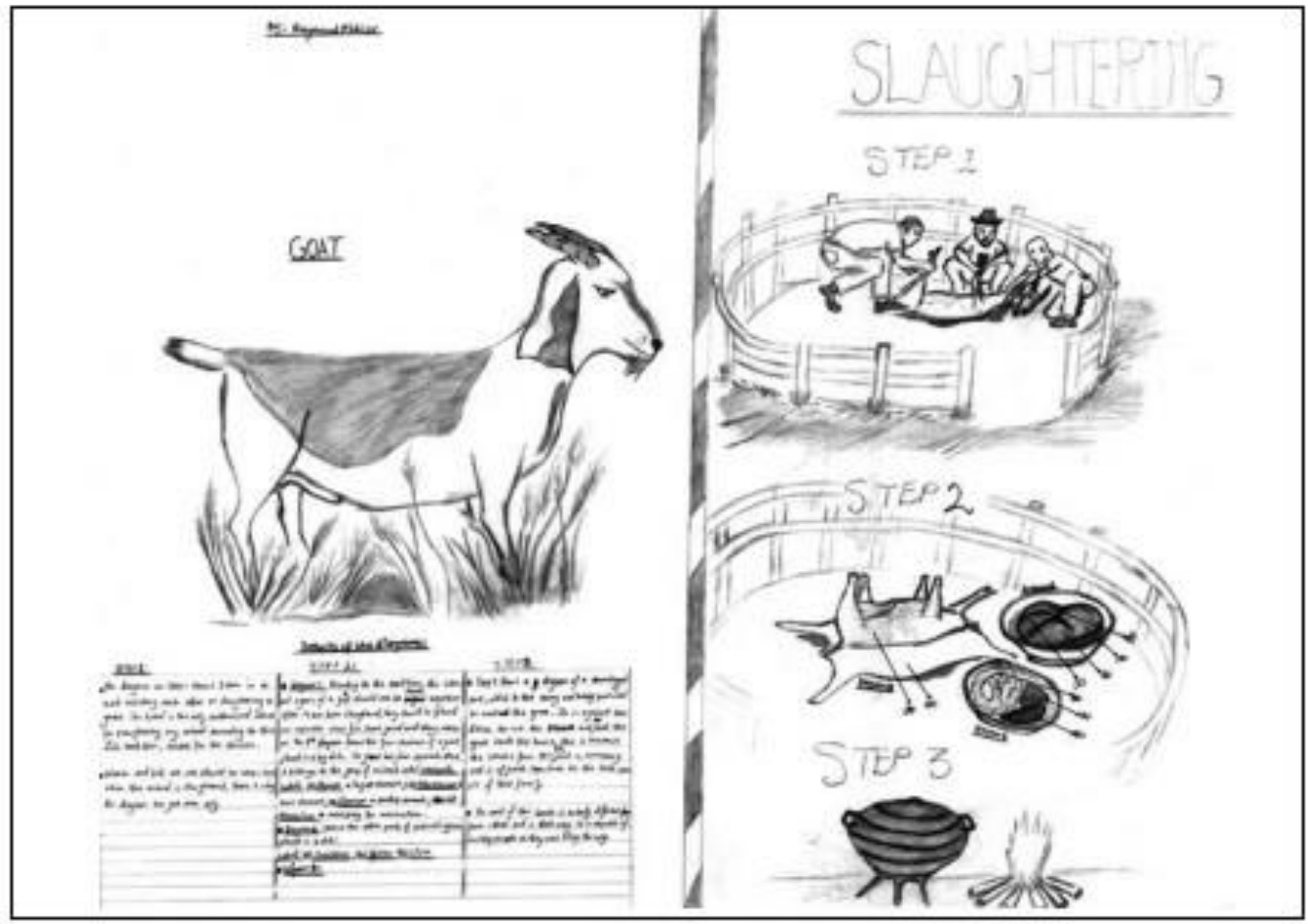

Figure 2: The text the students produced on the 'goat'

One group of students chose the 'face' as a Symbolic Object. They focused on facial expressions, adornments and modifications. In terms of facial expressions they highlighted the link between expression and emotion, emphasizing the face as a key signifier in human communication. In terms of adornments, they looked at make-up from a cross-cultural perspective. This included talking about South African initiation rituals for boys into

Lobola or 'bride wealth' is a traditional African practice where a bridegroom has to provide cattle or some other compensation to a prospective bride's family before marriage can take place. 
manhood, which involves painting the face white whilst in a state of transition, and red to signify the entry into manhood. They also mentioned head-dresses, for instance, worn by a chief at special occasions. Lastly, they looked at facial modifications, specifically in the form of piercings and scarification ('According to some cultures people who belong to a certain clan ... have to scar their faces to protect themselves from evil spirits'). The choice to focus on the 'face' is an interesting one as it highlights changing identities and the construction of identity from the resources available in the semiotic landscape. Facial adornments or modifications can indicate social demarcation (such as boys from men, or chiefs). But they can also indicate statements about individuality (such as, certain kinds of facial piercings). From these investigations, the students produced a poster as well as a 3-D object, a white paper-mache mask (See figure 3 below). The choice of a 'mask' points to highlighted tensions around identity -what is revealed and what is hidden, and the ability to construct one's own identity. The mask also has resonances in African traditionalist religions where a mask transforms the wearer - you assume another identity, rather than hiding or obscuring your own identity.

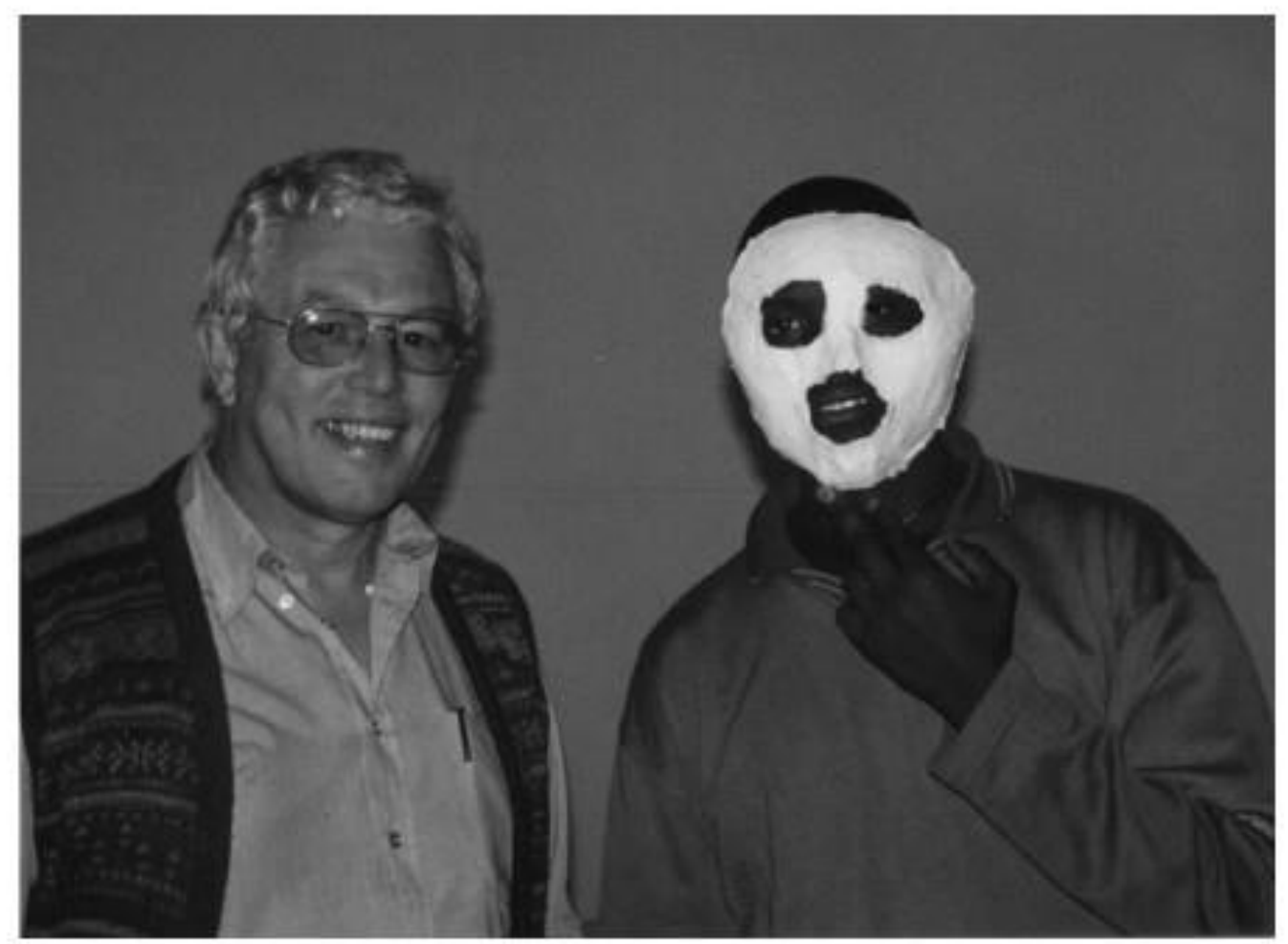

Figure 3: The students presenting their project on 'the face'.

The three 'objects' mentioned above (dreadlocks, goat, face) are strongly framed by a discourse of propriety. Propriety operates through the internal regulation of behaviour as the effect of a particular emotional, political, economic heritage which allows the subject 
to be located in a particular social universe (Mayol 1998: $16-21$ ). Change and propriety can often work in conflict with each other. Discussions around dreadlocks, for instance, are framed by who can and cannot wear them in terms of gender, generation, religion and context. They are also framed in terms of an uneasy mixture of aesthetics and morality (or 'respectability'): 'Dreadlocks are ones choice of hair style. As long as the hair is kept clean and neatly ... Just look respectable and I will respect you'. The discourse of propriety round the goat concerns who may take part in the ritualistic act of slaughtering (men, not women and children): 'women and kids are not allowed to come close when the animal is slaughtered'. The discussions around the face emphasize who can wear certain markers of status or belonging, and include many morality judgements about women wearing make-up. Gender, age and status thus demarcate the cultural and social spaces one is allowed to occupy.

Although propriety and convention feature strongly, it is also clear that the three discussed objects are all located in particular sociocultural contexts which are constantly changing. 'Ordinary culture hides a fundamental diversity of situations, interests, and contexts under the apparent repetition of objects that it uses' (De Certeau 1998: 256). Although cultural practices may appear constant, timeless and static, they are in fact reactualized in daily practice and are thus open to variation and contestation. The students' discussions on the objects and their subsequent textual productions highlighted the areas of contestation, the tensions between change and convention.

Opening up less regulated spaces in the curriculum

A 'cultural studies' project, such as the Symbolic Object project, can create a less regulated curriculum space, enabling students to draw on and experiment with a range of genres and modes. This is not always possible in the highly regulated genres in Higher Education. By 'less regulated spaces' I mean classroom environments which require open tasks with no strict generic guidelines specified. Also, classroom environments which place less emphasis on assessment and more emphasis on creativity and the use of students' own resources (Archer 2006a). The students can choose their own objects for investigation and talk about why certain objects are meaningful to them. Drawing on students' resources in creating this kind of reciprocal curriculum or 'literacy of fusion' (Millard 2006) opens up an opportunity for exchange of cultural and personal knowledge. In this less regulated space, students can also experiment with multimodal representation and draw on a range of discourses, such as propriety. In this way, the Symbolic Object project creates opportunities for students who may have been marginalized in the classroom to find a niche and a legitimate voice. An example of such a student was Mthoko, who was rather a fringe character in the class. He was a devout Rastafarian who read his bible up to four times a 
day. He came from a rural area in the Limpopo Province and embraced this rural 'traditional' identity. The project seemed to find resonances with him. He commented that this was 'just his type of thing' because many everyday signs, for instance, different colours have different meanings to him as a part of the Rasta community. Another student from a rural area grew up without electricity and studied throughout his school life by candle light. He spoke of the candle as a symbol of hope in his community. In general, the students enjoyed sharing the symbols of their community, and the class as a whole expressed interest in engaging with these.

However, this type of project tends to unleash a range of emotions in the classroom, such as strong moralistic impulses, anger about change, nostalgia for previous circumstances, humiliation about poverty. The crucial pedagogical challenge is to attempt to harness what has been unleashed. Kress and Van Leeuwen (2001) argue that moral discourses, for many in the West, are no longer systematically and explicitly shown. They have gone nderground and are hinted at or evoked through association. However, the students in this study were doing something rather different to this. They explicitly evoked strong moralistic discourses in the Symbolic Object projects where they were given free range to do what they wanted. What happens to the students' primary discourses like propriety, when they have to produce the more regulated academic genres? In general, there seemed to be a tempering or a demise of the overly moralistic aspect from the less regulated to the more regulated genres (such as written reports, and academic posters). There was a shift in focus to what the students deemed appropriate in talking about development. However, it could be useful to make an overt link between students' primary discourse of propriety and 'development', for instance. Propriety functions by specifying appropriate behaviour in relation to others and therefore upholds societal boundaries. It is in this upholding of the collective and not the individual that the discourse of propriety can be aligned with certain notions of development. In this view of development, the community and the common good are also emphasized over individual gain. This is the idea of sustainable development with an eye on subsequent generations.

By advocating a curriculum that sets up a dialogue with students' resources in order to 'harness' them, I do not mean simply using these resources, but encouraging students to critically interrogate them. For instance, identifying the underlying classification structure in texts (such as binaries) and looking at how these function ideologically. Elsewhere I have examined in more depth the ways in which the resources used in less regulated curriculum spaces can be utilized in more formal, high-stakes assessment curriculum tasks, and looked at how underlying systems of classification transfer across contexts, especially from the 'mythical' to the 'scientific' (Archer 2006b). The notions of convention 
and change that the Symbolic Object projects raise are important to explore in a course about rural development in a developing country like South Africa. 'Change' need not necessarily mean 'loss', but needs to be conceived of as additive. We need to be aware of and respect cultural norms and values, but at the same time, begin to look at these critically, with constructive lenses.

The Symbolic Object project can be adapted to the needs of a specific course and discipline in any context that engages in questions of identity, change, relativity of meaning, or material culture. Objects can be seen as catalysts for enabling student narratives and understandings to emerge. Engaging with students' representations of their chosen symbolic object is a refracted way of engaging with notions of culture and cultural practices in the classroom, as well as the tensions between convention and change. This 'cultural studies' perspective is important in educational and national contexts of rapid transition.

References

Achebe, C. (1975) Morning yet on creation day, London: Heinemann

Archer, A. (2006a) 'Opening up spaces through Symbolic Objects:

Harnessing students' resources in developing academic literacy practices

in Engineering', in English Studies in Africa, 49 (1)

Archer, A. (2006b) 'Change as additive: harnessing students 'mutimodal

semiotic resources in an engineering curriculum' in $L$. Thesen and $E$. van

Pletzen (eds.) Academic Literacies and Languages of Change, London:

Continuum pp224-251

Bangeni, B. and Kapp, R. (2005) 'Identities in transition: shifting

conceptions of home among 'black' South African university students', in

African Studies Review, 48 (3) pp1-19

Barnard, R. (2000) 'Contesting Beauty' in S. Nutall and C. Michael (eds).

Senses of Culture, Cape Town: Oxford University Press

Bennet, T. (1998) Culture. A reformer's science, London, Thousand Oaks,

New Delhi: Sage Publications

Bernstein, B. (1996) Pedagogy, Symbolic Control and Identity. Theory,

Research, Critique, London: Taylor and Francis

Csikszentmihalyi, Mihaly and Rochberg-Halton, Eugene (1981) The

Meaning of Things. Domestic symbols and the self, Cambridge, London,

New York: Cambridge University Press

De Certeau, M., Giard, L., Mayol, P. (1998) (Giard, L. (ed.) Tomasik, T.J.

trans.) The Practice of Everyday Life,Volume 2: Living and Cooking,

Minneapolis/London: University of Minnesota Press

Douglas, M. (1966) Purity and Danger: An Analysis of Concepts of

Pollution and Taboo, London: Routledge and Kegan Paul

Emmison, Michael and Smith, Philip (2000) Researching the Visual,

London, Thousand Oaks, New Delhi: SAGE Publications 
Foucault, M. (1972) (Smith, S. trans) The Archaeology of Knowledge, London: Tavistock

Hoskins, Janet (1998) Biographical Objects. How things tell the stories of people's lives, New York, London: Routledge

ledema, R. (2003) 'Multimodality, resemiotization: extending the analysis

of discourse as multi-semiotic practice', in Visual Communication, 2, 1

Kell, C. (2006) Crossing the margins: Literacy, Semiotics and the

recontextualisation of meanings

Kress, G. (2000) 'Multimodality', in B. Cope and M. Kalantzis. (eds.)

Multiliteracies. Literacy Learning and the Design of Social Futures,

London and New York: Routledge

Kress, G. and Van Leeuwen, T. (1996) Reading Images, The Grammar of Visual Design, London: Routledge

Kress, G. and Van Leeuwen, T. (2001) Multimodal Discourse. The Modes and Media of Contemporary Communication, London: Arnold

Lister, M. and Wells, L. (2001) 'Seeing beyond belief: cultural studies as an approach to analyzing the visual' in $T$. van Leeuwen and C. Jewitt

(Eds.) Handbook of Visual Analysis, London, Thousand Oaks, New Delhi: Sage

Mayol, P. (1998) 'Living' in M. De Certeau, L. Giard, P. Mayol. (L. Giard (ed.) T. J. Tomasik trans.) The Practice of Everyday Life. Volume 2: Living and Cooking, Minneapolis/London: University of Minnesota Press

Millard, E. (2006) 'Transformative Pedagogy: Teachers creating a literacy of fusion' in K. Pahl and J. Rowsell (eds.) Travel notes from the new literacies studies, Clevedon, Buffalo, Toronto: Multilingual Matters Ltd Thornton, R. (2000) 'Finding Culture' in S. Nuttall and C. Michael (eds.) Senses of culture: South African culture studies, Oxford: Oxford University Press

Acnowledgements

I am grateful to Lucia Thesen for her support and useful comments, as well as to the students on the course. This material is based upon work supported by the National Research Foundation (NRF) of South Africa and the University of Cape Town Research Committee. Any opinions, findings or recommendations expressed here are those of the author and the NRF does not accept any liability. 


\section{ASPECT END1008Z: SYMBOLIC OBJECTS PROJECT}

The Symbolic Objects Project got you to choose one object as a group and think about it as part of geographical, cultural and communicational landscapes. You had to produce a text which discussed both the physical, functional characteristics and uses of the object; as well as the symbolic, social and cultural meanings people attach to the object. You had to think about where and how these meanings are created. As a final step, you had to think about the relevance of this project to you as a student and engineer.

Please consider the following questions on your project and write individual responses to these. This means that you will get both a group mark for the project, as well as an individual mark, depending on the mark you get for this reflective written piece.

Marking Scheme for the Symbolic Objects Project

Group Project

Content of Project:

Presentation (and reflection thereon):

Divided by 3 for a mark out of a 100 .

QUESTIONS (1 hour to answer, each should be a paragraph or two in length depending on the detail required)

1. Write a reflection on the object as part of a range of physical, cultural and communicational landscapes; and how the object functions across different contexts, what meanings different people assign to it and why. 2. Write a justification for your choice of mode of presentation. For example, why did you choose to make a poster with drawings, or a video? What did this allow you to express about the topic, find out, that a different mode would not allow you to express?

3. Write a reflection on the relevance of the project for you as students and engineers. What did you learn from doing the project?

4. Have you noticed anything more about the object since you completed the project?

5. Given time, money and the opportunity, what would you have done differently on your project to improve it? 